Article

\title{
An Economic Model-Based Predictive Control to Manage the Users' Thermal Comfort in a Building
}

\author{
Yaser Imad Alamin ${ }^{1, \dagger}$, María del Mar Castilla ${ }^{2, \dagger}$, José Domingo Álvarez ${ }^{1, *, \uparrow}$ \\ and Antonio Ruano ${ }^{3,+}$ \\ 1 Department of Informatics, University of Almería, Agrifood Campus of International Excellence (ceiA3) \\ CIESOL Joint Centre University of Almería-CIEMAT, 04120 Almería, Spain; ya312@inlumine.ual.es \\ 2 Department of System Engineering and Automation, School of Engineering, University of Seville, \\ 41092 Seville, Spain; mcastilla4@us.es \\ 3 Faculty of Science and Technology, University of Algarve, Faro, Portugal and, IDMEC, \\ Instituto Superior Técnico, Universidade de Lisboa, 1049-001 Lisboa, Portugal; aruano@ualg.pt \\ * Correspondence: jhervas@ual.es; Tel.: +34-950-214-274 \\ + These authors contributed equally to this work.
}

Academic Editor: Giovanni Pau

Received: 2 December 2016; Accepted: 2 March 2017; Published: 7 March 2017

\begin{abstract}
The goal of maintaining users' thermal comfort conditions in indoor environments may require complex regulation procedures and a proper energy management. This problem is being widely analyzed, since it has a direct effect on users' productivity. This paper presents an economic model-based predictive control (MPC) whose main strength is the use of the day-ahead price (DAP) in order to predict the energy consumption associated with the heating, ventilation and air conditioning (HVAC). In this way, the control system is able to maintain a high thermal comfort level by optimizing the use of the HVAC system and to reduce, at the same time, the energy consumption associated with it, as much as possible. Later, the performance of the proposed control system is tested through simulations with a non-linear model of a bioclimatic building room. Several simulation scenarios are considered as a test-bed. From the obtained results, it is possible to conclude that the control system has a good behavior in several situations, i.e., it can reach the users' thermal comfort for the analyzed situations, whereas the HVAC use is adjusted through the DAP; therefore, the energy savings associated with the HVAC is increased.
\end{abstract}

Keywords: thermal comfort; energy efficiency; Predicted Mean Vote index; economic MPC

\section{Introduction}

Climate change, the decrease in fossil-based energy resources and the need for reducing greenhouse gas emissions require energy-efficient and smart building systems. For this reason, governments have shown, in recent years, a renovated attention to building energy efficiency. In the framework of the European Union (EU), these trends have led to the appearance of several European-wide regulations, which attempt to standardize the design and improvement of buildings to make them energy efficient. One of the most advanced and easiest to understand regulations in this field is Directive 2010/31/EU of the European Parliament and of the Council on the energy performance of buildings [1]. This directive promotes the energy performance of buildings [2] located within the European Union, taking into account outdoor climatic conditions and local peculiarities, as well as indoor climate requirements and profitability in terms of cost-effectiveness.

Therefore, buildings play a significant role in environmental impact since they consume $40 \%$ of the primary energy of the World, more than half used by heating, ventilation and air conditioning (HVAC) systems [3-5]. Therefore, the adoption of actions based on control systems for maintaining 
the comfort of their users has shown great potential to reduce this impact. In general, to improve buildings' performance from an energy efficiency point of view, it is necessary to take into account three different factors: main structural elements of the building, their use and the users of the building. The optimization and control methodologies for buildings can be classified into two approaches: (i) based on a real-time operation of the building, i.e., using a building energy management system; and (ii) an offline approach based on strategic choices for structural changes [6-8]. Additionally, it should be taken into account that users' comfort and energy efficiency are conflicting objectives since, in order to reach an optimal comfort situation, it is often required to increase energy consumption. Thus, many of these control systems are based on model-based predictive control (MPC), which tries to optimize a cost function to find a tradeoff between users' comfort and energy consumption without putting users' welfare at risk.

MPC is one of the most extended techniques for comfort control on real-time operation since it uses a model of the system, noise and disturbances, in order to perform predictions of the future output. These predictions are incorporated within a cost function, which is related to closed loop behavior and control effort and that is minimized as a function of the future control signals' sequence taking into account constraints defined in the problem. Finally, a receding horizon strategy is implemented to achieve feedback. It consists of the following: at each time, the horizon is displaced towards the future, which involves the application of the first control signal of the sequence calculated at each step, while the remaining signals are not used. At the next control instant, the horizon is displaced towards the future, and the controller with new measurements solves and updates the optimal control problem. In Camacho and Bordons [9], this strategy is widely described, and the possibilities that it offers, as a motivation for its use, are explained in detail.

In the last few years, it is possible to find in the literature some works dealing with MPC for controlling the users' thermal comfort. Among them, it is possible to point out as examples the work presented in Pčolka et al. [10], where an MPC that uses a linear time-dependent model is introduced; with this controller, the authors try to obtain predictions closer to reality than the ones obtained from a linear time-invariant model; at the same time, the computational complexity associated with the optimization procedure does not increase, since the optimization task remains convex. Results obtained with the proposed controller are compared with the ones obtained through a non-linear MPC. The obtained results demonstrated that the proposed linear MPC reaches a reasonable tradeoff between the optimal solution and the time cost associated with the optimization problem, specifically in the case of centralized MPC for large buildings. The benefits that the use of an MPC can offer in the control of aged residential buildings designed with poor construction material and systems are shown and commented on in Carrascal et al. [11]. In this work, RCmodels are used for modeling dwellings. The results indicate that the MPC obtains energy savings varying between $10 \%$ and $15 \%$ with respect to simple on/off controllers. Finally, a simulation-based MPC procedure is presented in Ascione et al. [12], in which the EnergyPlus software, which is a building performance simulation tool, is combined with an optimization engine, in this case MATLAB ${ }^{\circledR}$, to achieve a multi-objective optimization of the HVAC system's daily operation; specifically, the MPC tries to optimize the operating cost for space heating and the thermal comfort, quantified by the predicted percentage of dissatisfied (PPD). The results show that the proposed MPC is able to reduce the operating cost for space heating equal to $56 \%$, whereas the PPD is reduced about $8 \%$.

However, not only the MPC is used at the time to control the users' thermal comfort; in Afram and Janabi-Sharifi [13], optimal set-points and dead-band settings are found for on/off controllers in order to improve thermal comfort, whereas energy consumption is minimized by reducing the switching frequency of HVAC equipment. In Michailidis et al. [14], an automated control calibration procedure for building optimization and control systems is proposed. Through this methodology, no human intervention or simulation model is required for the initial deployment of the controller. Real results from an Israeli commercial building check the performance of the proposed methodology. A neural network temperature predictor is combined with a fuzzy controller in Marvuglia et al. [15] in 
order to maintain thermal comfort in an office building. The predictor is able to forecast accurately indoor temperature during summer and winter seasons. The fuzzy controller is fed with these predictions in order to calculate a suitable control action. Another fuzzy logic controller is used in Jazizadeh et al. [16], which uses building occupants' personalized thermal profiles in order to improve its efficiency. The results show a reduction in daily average airflow rates by $26 \%$ when the users' personalized thermal profiles are used instead of predefined ones.

In this work, an economic MPC for users' comfort in buildings is presented. The main strength of the proposed approach, with respect to the ones cited and commented on in this section, is the use of the day ahead price (DAP) to take into account the electricity price; in this way, the controller is able to calculate how much money it costs the required energy to reach the desired thermal comfort associated with the HVAC. Specifically, the MPC calculates the optimal fan coil speed to get users' thermal comfort, whereas the energy consumption of the HVAC is minimized. The performance of the proposed control system is tested through simulation tests with a non-linear model of a bioclimatic building. Specifically, one of the most representative rooms of the Solar Energy Research Center, in Spanish: Centro de Investigación en Energía SOLar-CIESOL, has been used. This room has been equipped with actuators to control the comfort inside the building (HVAC systems, automated windows opening and shading devices and adjustable artificial lighting). It is important to highlight that the proposed control methodology can be applied to other buildings, not necessarily in a bioclimatic one. The only requirement is that the building has a suitable network of sensors in order to be able to estimate the predicted mean vote (PMV) index. The obtained results are promising, and the next step will be to implement the control system into the supervisory control and data acquisition (SCADA) system of the CIESOL building in order to obtain real results.

The paper is organized as follows. After the Introduction presented before, the methodology used in this work, i.e., the necessary preliminary concepts to this work, the non-linear model used as a test-bed simulator and the control architecture, are described in depth in Section 2, whereas Sections 3 and 4 are devoted to showing the main results and to discussing the conclusions and future works obtained from this work, respectively.

\section{Methodology}

The main aim of this section is to introduce the theoretical background, as the estimation of thermal comfort through the PMV index and the basic concepts of MPC (see Section 2.1) and the steps followed to develop the work presented in this paper. More in detail, Sections 2.2 and 2.3 provide a brief description about the scope of research and the non-linear model used in this work as a test-bed simulator. The control architecture is described in depth in Section 2.4.

\subsection{Preliminary Concepts}

This paper proposes a control architecture to maintain an appropriate level of thermal comfort for the users of a bioclimatic building, but it can also be used in a regular building with a suitable network of sensors. Hence, the main objective of this section is to introduce the theoretical background necessary for a correct understanding of the work presented in this paper. More specifically, Section 2.1.1 is devoted to a detailed analysis of thermal comfort concept and the methodology used for its estimation. Section 2.1.2 introduces the main concepts and definitions related to MPCs from a general point of view.

\subsubsection{Thermal Comfort}

In general, users' comfort conditions in a certain environment can be defined as a function of several factors, such as indoor-air quality, thermal and visual comfort. Besides, it is a critical issue that should be taken into consideration, since users' comfort is directly related to their productivity and, moreover, to their physical and psychological well-being. Therefore, users' comfort is influenced by a wide variety of processes, including physiological, physical, as well as psychological ones. Hence, comfort can be considered as a cognitive process [17]. 
Thermal comfort is defined by international standards (ASHRAE 55 [18] and ISO 7730 [19]) as "That condition of mind which expresses satisfaction with the thermal environment" [20]. Furthermore, from that definition, it can be inferred that thermal comfort depends on various conditions, such as the surrounding environment (temperature, relative humidity, air velocity) and the season of the year. Nonetheless, it is possible to find in the literature several studies [17] that have demonstrated that even with the existing differences among living environments and culture around the world, the indoor-air temperature selected by people under comparable circumstances of clothing, physical activity and climate for a thermal comfort situation is very similar.

Therefore, it is possible to define appropriate mechanisms to calculate thermal comfort conditions. The most widespread one is the PMV index developed by Fanger [21] during the 1970s to guarantee humans' thermal comfort. This index is based on the energy balance of the human body with its surrounding environment [22], and thus, it guarantees a thermal comfort situation by predicting the average thermal sensation response of large groups of people exposed to different thermal conditions for a long period of time [19].

The value provided by the PMV index is within a seven-point thermal sensation scale, which is shown in Table 1. Hence, to ensure thermal comfort, international standards $[18,19]$ recommend to maintain the PMV index at Level 0 with a tolerance of \pm 0.5 [23]. Moreover, the PMV index is influenced by the six variables that appear in Table 2, that is metabolic rate $(M)$, clothing insulation $\left(I_{c l}\right)$, air temperature $\left(T_{a_{i n}}\right)$, mean radiant temperature $\left(T_{m r}\right)$, air velocity $\left(v_{a_{i n}}\right)$ and air relative humidity $\left(H_{r}\right)$. Most of these variables can be obtained through sensors or by means of a simple methodology [24]. However, although human activity and clothing insulation variables cannot be easily calculated, since they depend on the precise location of people and the season of the year, tabulated values for them can be obtained from manuals and international standards $[19,21]$. For instance, the typical values associated with clothing insulation for the winter and summer period are 1.0 clo (clothing insulation unit) and 0.5 clo, respectively. In addition, for characteristic office activities, a metabolic rate equal to 1.0 met is fixed. The PMV index is calculated according to Equation (1) $[18,19]$.

$$
P M V=[0.303 \exp (-0.036 M)+0.028] L
$$

Table 1. PMV index thermal sensation scale.

\begin{tabular}{cc}
\hline PMV Index Value & Sensation \\
\hline+3 & Hot \\
+2 & Warm \\
+1 & Slightly warm \\
\pm 0 & Neutral \\
-1 & Slightly cool \\
-2 & Cool \\
-3 & Cold \\
\hline
\end{tabular}

Table 2. Variables that influence thermal comfort [25].

\begin{tabular}{cccc}
\hline Variable & Symbol & Range & Units \\
\hline Metabolic rate & $M$ & $0.8-4$ & $\operatorname{met}\left(\mathrm{W} / \mathrm{m}^{2}\right)^{\mathrm{a}}$ \\
Clothing insulation & $I_{c l}$ & $0-2$ & $\mathrm{clo}\left(\mathrm{m}^{2} \cdot{ }^{\circ} \mathrm{C} / \mathrm{W}\right)^{\mathrm{b}}$ \\
Indoor air temperature & $T_{a_{i n}}$ & $10-30$ & ${ }^{\circ} \mathrm{C}$ \\
Mean radiant temperature & $T_{m r}$ & $10-40$ & ${ }^{\circ} \mathrm{C}$ \\
Air velocity & $v_{a_{i n}}$ & $0-1$ & $\mathrm{~m} / \mathrm{s}$ \\
Air relative humidity & $H_{r}$ & $30-70$ & $\%$ \\
\hline \multicolumn{2}{c}{ a 1 met $=58.15 \mathrm{~W} / \mathrm{m}^{2} ;{ }^{\mathrm{b}} 1 \mathrm{clo}=0.155 \mathrm{~m}^{2} .{ }^{\circ} \mathrm{C} / \mathrm{W}}$.
\end{tabular}

In the previous equation, $M$ represents the metabolic rate of a human being expressed in $\left(\mathrm{W} / \mathrm{m}^{2}\right)$, and $L$ symbolizes the existing difference between the internal heat production and loss that occurs in 
a human body when the person is subjected to certain thermal conditions in $\left(\mathrm{W} / \mathrm{m}^{2}\right)$. More specifically, this thermal load, $L$, can be calculated as is shown in Equation (2).

$$
\begin{aligned}
L & =(M-Q)-0.0014 M\left(34-T_{a_{i n}}\right)-1.72 \times 10^{-5} M\left(5867-p_{a}\right) \\
& -0.42(M-Q-58.15)-39.6 \times 10^{-9} f_{c l}\left[\left(T_{c l}+273\right)^{4}-\left(T_{m r}+273\right)^{4}\right] \\
& -3.05 \times 10^{-3}\left[5733-6.99(M-Q)-p_{a}\right]-f_{c l} h_{c}\left(T_{c l}-T_{a_{i n}}\right)
\end{aligned}
$$

where $Q$ is the work performed by human muscles for the development of a certain task in $\left(\mathrm{W} / \mathrm{m}^{2}\right)$ and $p_{a}$ represents the partial water vapor pressure in the indoor air expressed in $(\mathrm{Pa})$. This parameter is calculated from indoor-air relative humidity, $H_{r}$, since it can be defined as the relationship between partial and saturated water vapor pressures in the air at a given temperature $T_{a_{i n}}$ in $(\mathrm{K}) ; T_{m r}$ stands for the mean radiant temperature in $(\mathrm{K}) ; h_{c}$ represents the convective heat transfer coefficient in $\left(\mathrm{W} /\left(\mathrm{m}^{2} \mathrm{~K}\right)\right) ; f_{c l}$ is the clothing area factor $(-)$; and $T_{c l}$ stands for the clothing surface temperature in $(\mathrm{K})$, which can be estimated according to Equation (3).

$$
\begin{aligned}
T_{c l} & =35.7-0.028(M-Q)-0.155 I_{c l}\left[f_{c l} h_{c}\left(T_{c l}-T_{a_{i n}}\right)\right. \\
& \left.+39.6 \times 10^{-9} f_{c l}\left[\left(T_{c l}+273\right)^{4}-\left(T_{m r}+273\right)^{4}\right]\right]
\end{aligned}
$$

Finally, in Equations (2) and (3), $h_{c}$ represents the convective heat transfer coefficient expressed in $\left(\mathrm{W} /\left(\mathrm{m}^{2} \mathrm{~K}\right)\right)$, and $f_{c l}$ is the clothing area factor in $[-]$, which can be calculated as can be observed in Equations (4)-(6):

$$
\begin{aligned}
h_{c} & = \begin{cases}2.38 \cdot\left(T_{c l}-T_{a_{i n}}\right)^{0.25}, & A>12.1 \cdot \sqrt{V_{i n}} \\
12.1 \cdot \sqrt{V_{i n}}, & A \leq 12.1 \cdot \sqrt{V_{i n}}\end{cases} \\
A & =2.38 \cdot\left(T_{c l}-T_{a_{i n}}\right)^{0.25} \\
f_{c l} & = \begin{cases}1.0+0.2 \cdot I_{c l}, & I_{c l} \leq 0.5 \mathrm{clo} \\
1.05+0.1 \cdot I_{c l}, & I_{c l}>0.5 \mathrm{clo}\end{cases}
\end{aligned}
$$

where $I_{c l}$ is the clothing insulation in $\left(\mathrm{clo}=\left(\mathrm{m}^{2} \mathrm{~K}\right) / \mathrm{W}\right)$ and $\mathrm{V}_{\text {in }}$ represents the air velocity in $(\mathrm{m} / \mathrm{s})$.

\subsubsection{Model Predictive Control: Basic Concepts and Definitions}

MPC is one of the most widespread control techniques within industrial and academic fields [9]. Generally, MPC is characterized by explicitly using a model of the process in order to calculate the future control signals' sequence by minimizing a certain objective function [26]. In addition, it uses a receding horizon strategy, that is, at each sample time, the first control signal of the estimated sequence is applied to the system, and the other ones are discarded [9].

Therefore, MPC algorithms use a predicted output data vector $(\hat{\mathbf{Y}})$ through a prediction horizon $(N)$ and a vector composed of future changes in the control action $(\Delta \mathbf{u})$ along a control horizon $\left(N_{u}\right)$ :

$$
\hat{\mathbf{Y}}=\mathbf{F}+\mathbf{G} \Delta \mathbf{u}
$$

where the free $(\mathbf{F})$ and forced $(\mathbf{G})$ response matrices are calculated by means of different methods as a function of the selected algorithm. On the one hand, it should be emphasized that, $\hat{\mathbf{Y}}=\mathbf{F}$ represents the obtained response when the future control actions are zero. On the other hand, $\hat{\mathbf{Y}}=\mathbf{G} \Delta \mathbf{u}$ is the response obtained when the initial conditions are considered null.

Hence, the availability of a model of the process is a cornerstone within the MPC field. Furthermore, this model should precisely capture the main dynamics of the controlled process and, simultaneously, be simple enough to not increase the computational cost derived from estimating future control signals [26]. 


\subsection{Scope of the Research: The CIESOL Building}

In this paper, an economic MPC-based control architecture has been proposed to maintain appropriate thermal comfort conditions inside a certain environment and, simultaneously, to keep energy costs derived from the use of the HVAC system within a controlled range. Besides, to evaluate the performance of the proposed control strategy, it has been tested in simulation inside a characteristic room of the CIESOL building [27]. CIESOL is a solar energy research center placed inside the Campus of the University of Almería in the southeast of Spain; see Figure 1.

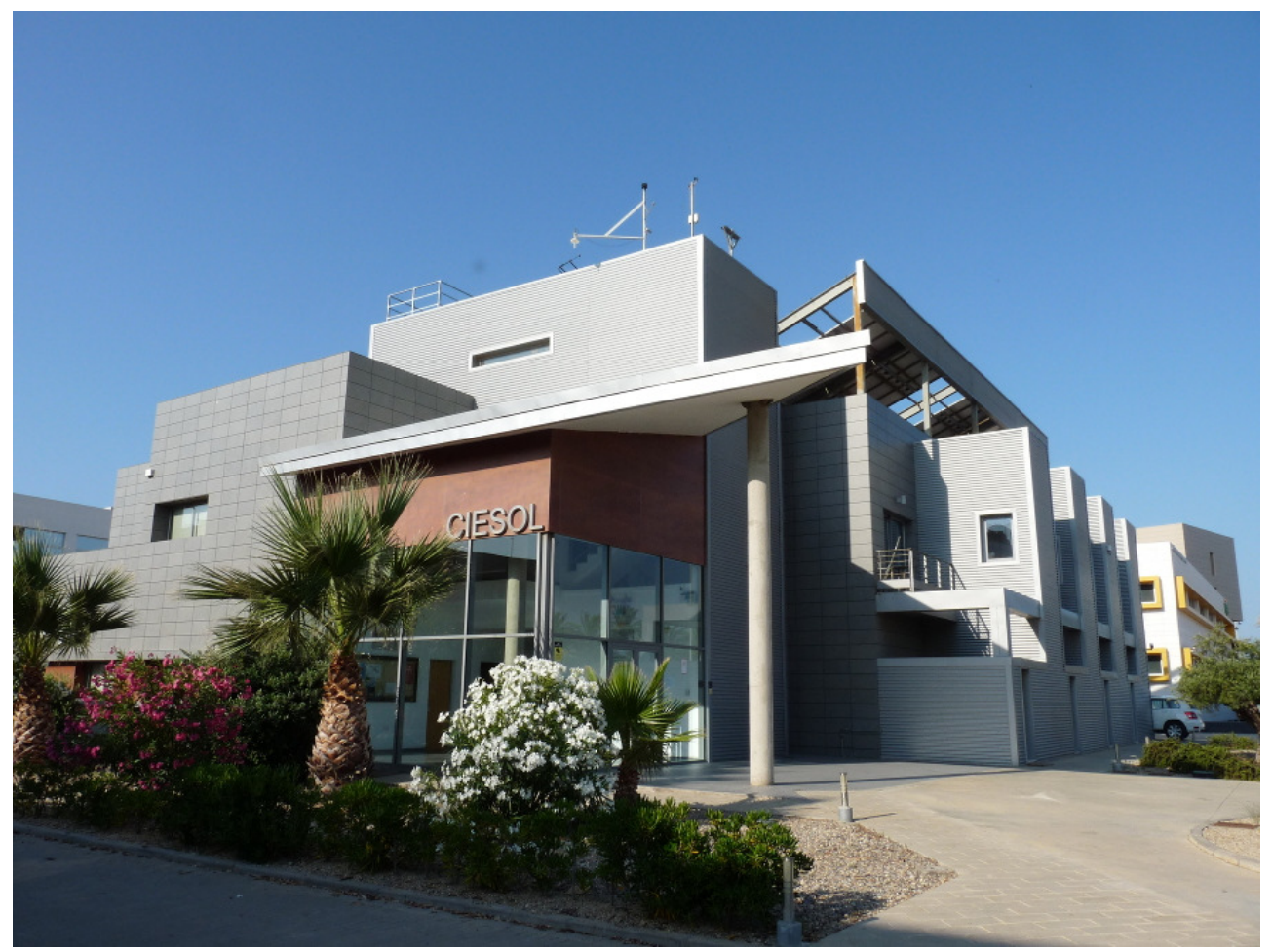

Figure 1. The CIESOL building.

More specifically, this building is divided into two different floors with a total surface approximately equal to $1072 \mathrm{~m}^{2}$. In addition, it has been designed to be a nearly-zero energy building (NZEB), and thus, it has several bioclimatic criteria, such as the use of photovoltaic panels to produce electricity and an HVAC system based on solar cooling, which is composed of a solar collector field, a hot water storage system, a boiler and an absorption machine with its refrigeration tower. Therefore, this HVAC system is able to produce heat or cold air for the whole building as a function of the demanded necessities. To do that, heat or cold water flows around the building, and at each room, it goes through a fan coil unit. This fan coil unit allows one to introduce air at a certain temperature inside each room by regulating both the amount of water that flows through it (by means of a two-way valve) and the volume of air that is introduced in the room (by means of a three-position fan); see Figure 2a. Moreover, the building also uses several passive strategies, such as different enclosures as a function of their orientation and a crossed-ventilation strategy for the passive fitting-out through the hottest months.

Furthermore, the CIESOL building works as a research center, which deals with the study of the implemented bioclimatic strategies, the analysis of their influence over energy efficiency and greenhouse effect gas reduction, as well as the development of optimization techniques to increase the ratio of renewable energies' use against conventional ones. For this reason, it uses a wide network of sensors and actuators (see Figure 2) whose measured data are stored in a database by means of a measurement and acquisition software [26]. More specifically, the building has a meteorological 
station composed of different types of sensors (e.g., temperature, relative humidity, direct and diffuse irradiance, $\mathrm{CO}_{2}$ concentration, etc.). Besides, five representative rooms of the building have been selected, and a large network of sensors and actuators has been installed. For instance, these rooms use air temperature, plane radiant temperature, globe temperature, relative humidity sensors, etc., as actuators, a fan coil unit and automatized windows and blinds.

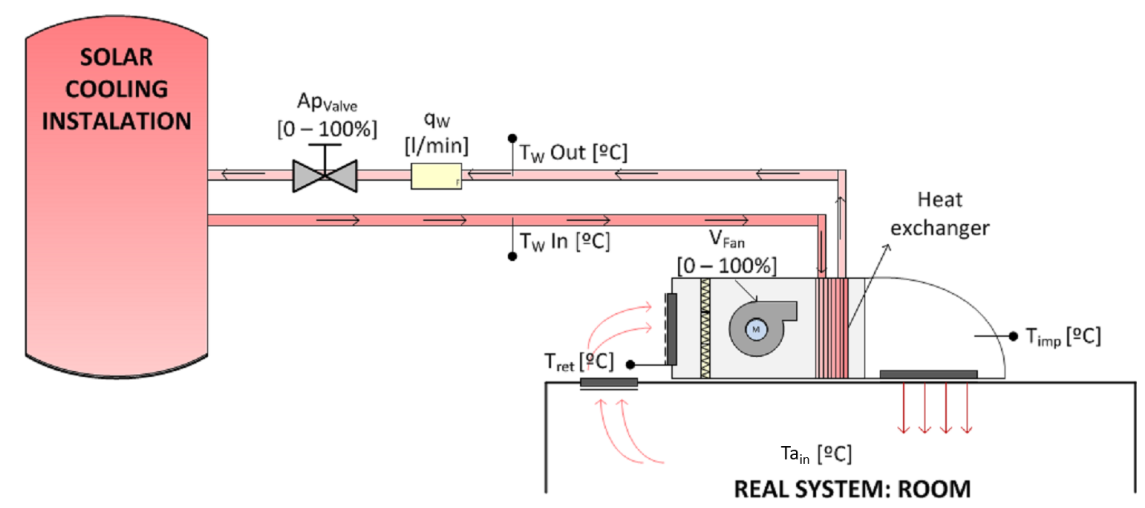

(a)

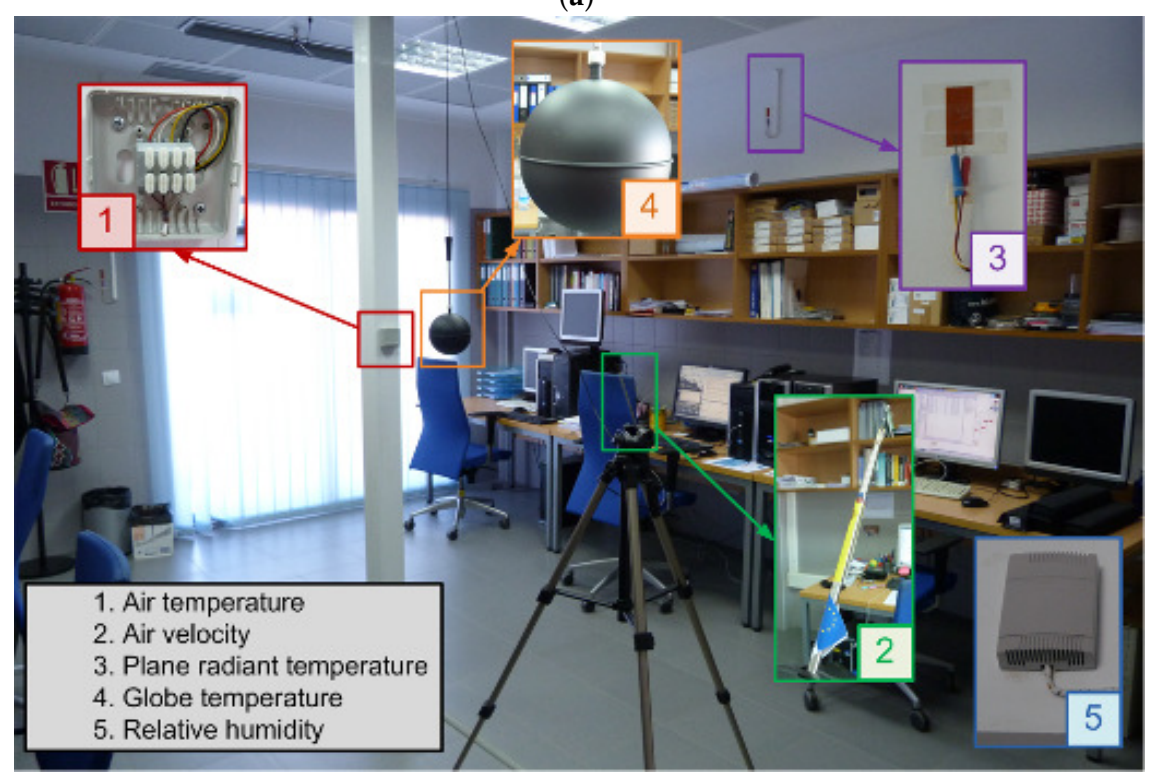

(b)

Figure 2. Characteristic room of the CIESOL building. (a) Scheme of a fan coil unit; (b) main sensors.

In order to test the control architecture proposed in this paper, one of the representative rooms of the CIESOL building has been selected as a reference. This room was chosen among the characteristic ones mainly due to its occupancy profile. More in detail, this room works as an office, and it is placed in the upper floor of the CIESOL building. In addition, it is characterized by having a north orientation, a volume of $76.8 \mathrm{~m}^{3}$ and a window with a total surface of $2.15 \times 2.09 \mathrm{~m}^{2}$. Moreover, it consists of a fan coil unit able to regulate the PMV index by controlling the fan coil speed. Hence, it has been required to obtain a model able to act as a simulator, that is to represent precisely the indoor temperature dynamic behavior. To do that, a model based on fundamental principles has been developed. A brief description of the fundamental principles model used can be found in Section 2.3.

\subsection{Room Simulator: Model Based on First Principles}

As was mentioned previously, the control architecture presented in this paper has been evaluated through simulation tests inside a characteristic room of the CIESOL building: see Section 2.2. To do 
that, it is necessary to have at disposal a simulator able to exactly capture the dynamic behavior of the main involved environmental variables. More specifically, in this paper, an indoor air temperature model based on first principles has been used as the simulator.

In general, a closed environment, such as a room, can be defined as a complex system composed of different types of elements, such as, walls, windows, actuators, etc. Besides, it is also very important to take into consideration several factors as outside climate and the environmental conditions in the adjacent rooms. Afterwards, the relations among different elements can be estimated by means of heat (convection, conduction and radiation) and mass transfer laws. A description of the indoor air temperature balance equations is shown in Equations (8)-(14):

$$
\begin{gathered}
m_{a} \cdot C_{p_{a}} \cdot \frac{d T_{a_{i n}}}{d t}=Q_{\text {glass }}+Q_{H V A C}+Q_{\text {nvnt }}+Q_{\text {conv }}+Q_{i G a i n}+Q_{\text {inf }} \\
Q_{\text {glass }}=f_{1}\left(T_{a_{i n}}, T_{\text {out }}, I_{d r}, I_{d f}, I_{r f}\right) \\
Q_{H V A C}=f_{2}\left(T_{i m p}\right) \\
Q_{\text {nvnt }}=f_{3}\left(T_{a_{i n}}, T_{\text {out }}\right) \\
Q_{\text {conv }}=f_{4}\left(T_{a_{i n}}, T_{N}, T_{S}, T_{W}, T_{E}, T_{g r}, T_{c}\right) \\
Q_{i G a i n}=f_{5}\left(T_{a_{i n}}, T_{m r}, H_{r}, N_{p}\right) \\
Q_{\text {inf }}=f_{6}\left(T_{a_{i n}}, T_{\text {out }}\right)
\end{gathered}
$$

The meaning of the different parameters that appear in the previous equations is shown in Table 3. Specifically, as can be observed in Equation (8), variation in the indoor air temperature variable can be calculated as a function of: (i) the heat gain due to the windows, $Q_{\text {glass }}$; (ii) the heat exchanged by means of the forced ventilation, $Q_{H V A C}$; (iii) the heat gain through natural ventilation, $Q_{\text {nont }}$; (iv) the heat transferred by means of convection with the walls $Q_{\text {conv }} ;(\mathrm{v})$ the heat gain due to internal gains (people, electrical appliances, lights, etc.), $Q_{i G \text { ain }}$; and (vi) the heat transferred through infiltration, $Q_{\text {inf }}$; see Figure 3. A detailed description of the procedure to estimate each one of these terms can be found in [26].

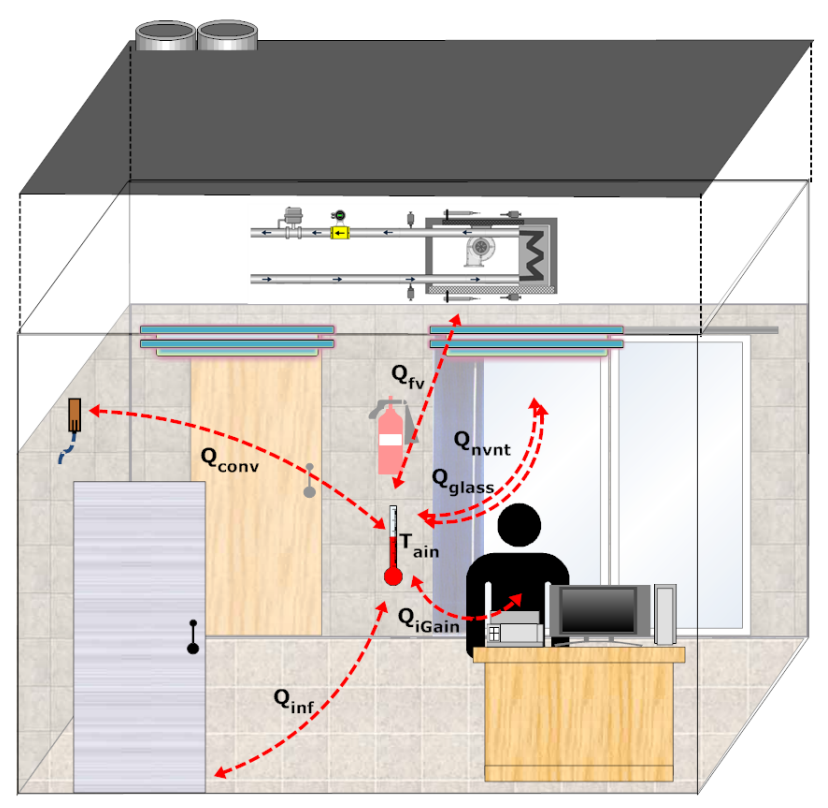

Figure 3. Heat balance inside a room. Source: [26]. 
Table 3. Parameters for the room model [28].

\begin{tabular}{ccc}
\hline Parameters & Description & $\mathrm{SI} \mathrm{Units}$ \\
\hline$C_{p_{a}}$ & Air specific heat & $\mathrm{J} / \mathrm{kg} \cdot \mathrm{K}$ \\
$H_{r}$ & Relative humidity & $\%$ \\
$I_{d f}$ & Diffuse irradiance & $\mathrm{W} / \mathrm{m}^{2}$ \\
$I_{d r}$ & Direct irradiance & $\mathrm{W} / \mathrm{m}^{2}$ \\
$I_{r f}$ & Reflected irradiance & $\mathrm{W} / \mathrm{m}^{2}$ \\
$m_{a}$ & Air mass & $\mathrm{kg}$ \\
$N_{p}$ & Number of people & - \\
$Q_{\text {conv }}$ & Heat gain by free convection through walls & $\mathrm{W}$ \\
$Q_{g l a s s}$ & Heat gain through the window & $\mathrm{W}$ \\
$Q_{H V A C}$ & Heat gain by forced ventilation & $\mathrm{W}$ \\
$Q_{i G a i n}$ & Heat gain due to internal gains & $\mathrm{W}$ \\
$Q_{i n f}$ & Heat gain due to infiltrations & $\mathrm{W}$ \\
$Q_{n v n t}$ & Heat gain by natural ventilation & $\mathrm{W}$ \\
$T_{a_{i n}}$ & Indoor air temperature & $\mathrm{K}$ \\
$T_{c}$ & Ceiling plane radiant temperature & $\mathrm{K}$ \\
$T_{E}$ & East plane radiant temperature & $\mathrm{K}$ \\
$T_{g r}$ & Ground plane radiant temperature & $\mathrm{K}$ \\
$T_{i m p}$ & Impulse air temperature & $\mathrm{K}$ \\
$T_{m r}$ & Mean radiant temperature & $\mathrm{K}$ \\
$T_{N}$ & North plane radiant temperature & $\mathrm{K}$ \\
$T_{S}$ & South plane radiant temperature & $\mathrm{K}$ \\
$T_{W}$ & West plane radiant temperature & $\mathrm{K}$ \\
$T_{\text {out }}$ & Outdoor air temperature & $\mathrm{K}$ \\
\hline
\end{tabular}

Hence, thermal comfort control (PMV) will be performed by an indirect control of the indoor air temperature $\left(T_{a_{i n}}\right)$ by means of the fan coil speed $\left(V_{F a n}\right)$. Finally, there will be some disturbances that influence the control process, such as the outdoor air temperature $\left(T_{o u t}\right)$, the solar radiation $\left(I_{d r}, I_{d f}\right.$ and $\left.I_{r f}\right)$, the relative humidity $\left(H_{r}\right)$ and the number of people inside the room $\left(N_{p}\right)$.

\subsection{Control System Architecture}

The primary control objective of the work presented in this paper is the development of a control system able to provide an appropriate thermal comfort level for the users of a bioclimatic building and, simultaneously, to optimize the economic cost derived from maintaining this thermal comfort situation.

In previous works, different predictive control strategies have been compared by the evaluation of several cost functions [29]. Concretely, in that work, the main goal was to maintain thermal comfort within an appropriate zone defined by the PMV index minimizing, at the same time, energy consumption. To do that, linearized models around an operating point, which relate indoor air temperature (K) and fan coil speed (\%), have been used. Nevertheless, in the work presented in this paper, a more advanced thermal comfort control architecture within sustainable buildings has been proposed; see Figure 4. More specifically, it has been supposed that in order to maintain adequate daily environmental conditions for the users of a building, it is required to consume a certain amount of energy. Additionally, it should be taken into account that energy price is not constant along the whole day, but it changes dynamically as a function of supply and demand instead. Hence, the main goal of the proposed control architecture is to decide, based on the energy day ahead price (DAP), when is more beneficial (in economic terms) to consume the necessary amount of energy in order to reach an acceptable thermal comfort level. To do that, it has been supposed that the only actuator able to regulate thermal comfort is the HVAC system based on solar cooling [26].

Therefore, the proposed architecture is based on an economic model-based predictive control scheme (see Figure 4 ) able to estimate optimal fan coil speed set-points $\left(V_{F a n}\right)$ in (\%), which allows the users to maintain adequate PMV levels in the building. More specifically, these fan coil speed set-points 
influence the indoor air temperature, and thus, the PMV index as a function of other environmental parameters; see Equation (1).

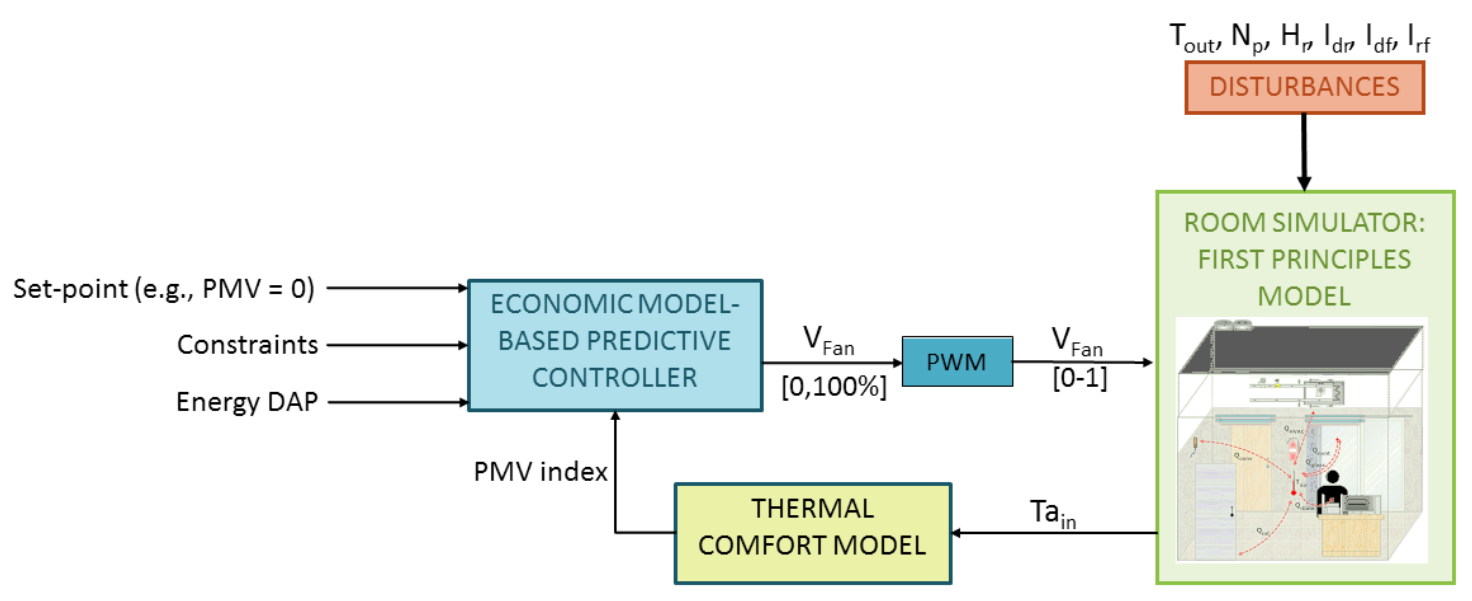

Figure 4. Control system architecture.

\section{Economic Model-Based Predictive Controller}

The developed control architecture is based on an economic model-based predictive controller. Therefore, it is necessary to have a simple enough model of the process to be used within the proposed control approach. Moreover, the solar cooling installation of the CIESOL building has two different operation modes: summer and winter. Hence, two linear-time invariant (LTI) models around an operation point have been estimated through classical identification techniques [30] from the model based on first principles used as a simulator; see Section 2.3. More in detail, they express the existing relation between the PMV index (-) and fan coil speed (\%). For example, in Equation (15), the continuous-time transfer function in the Laplace variable sfor the summer period linearized model is shown:

$$
G(s)=\frac{Y_{P M V}(s)}{U(s)}=\frac{k}{\tau s+1} ;\left\{\begin{array}{l}
k=-0.006716 \\
\tau=252.2
\end{array}\right.
$$

where the static gain $(k)$ is in (PMV/\%) and the time constant $(\tau)$ is expressed in (s). The LTI models used in this work have been demonstrated to provide in simulation an appropriate performance in spite of being very simple LTI models, since the associated uncertainty does not strongly interfere with the fulfillment of closed-loop system.

Therefore, the proposed control architecture provides fan coil speed set-points to the fan coil unit, which allows one to reach optimal PMV index values. In the case of study proposed in this paper, the cost function defined by Equation (16) is used. More specifically, this cost function tries to find out the best future control signal $(u)$ that minimizes the tracking error, that is the existing difference between the predicted output $\left(\hat{Y}_{P M V}\right)$, the PMV index and the reference value $\left(P M V_{\text {ref }}\right)$. Moreover, the future control signals, the fan coil speed $\left(V_{F a n}\right)$, are penalized as a function of a parameter $(\mathrm{Cee})$, which is estimated based on energy DAP. Concretely, it represents the energy price per speed percentage $(€ / \%)$ and is obtained as the product between energy price per watt $(€ / W)$ and the consumption in watts associated with the fan coil speed $(W / \%)$. Finally, the proposed cost function is normalized by means of weighting parameters.

$$
J=\sum_{j=1}^{N} \delta(j)\left[\widehat{Y}_{P M V}(k+j \mid k)-P M V_{r e f}(k+j \mid k)\right]^{2}+\sum_{j=1}^{N_{u}} \lambda(j) C e e(j)[u(k+j-1)]^{2}
$$

In the previous equation, the first term on the right side is the set-point tracking, i.e., the difference between the predicted output and the desired reference, whereas the second term is considered the 
control effort. $N$ and $N_{u}$ represent the prediction and control horizons, respectively; $\widehat{Y}_{P M V}(k+j \mid k)$ is the predicted output (the PMV index) estimated at sample time $k+j$ with the information available at time $k$ by means of a discrete version of the continuous linear model given by Equation (15); $P M V_{\text {ref }}(k+j \mid k)$ represents the future PMV index reference; $u(k+j-1)$ is the future control signal, that is fan coil speed $\left(V_{F a n}\right) ; \delta(j)$ and $\lambda(j)$ are the weights associated with set-point tracking and control effort, respectively. More specifically, for the different simulations performed in the framework of this paper, the previously mentioned parameters have been fixed to the following values: (i) prediction horizon: $N=20$; (ii) control horizon: $N_{u}=5$; (iii) sample time: $t_{s}=120 \mathrm{~s}$; (iv) weighting parameters: $\delta=0.25$ and $\lambda=0.002$.

Furthermore, as the output predictions, $\widehat{Y}_{P M V}(k+j \mid k)$, are done through the linear transfer function shown in Equation (15), this turns Equation (16) into a linear optimization problem subject to the constraints given by Equations (17) and (18). The first constraint (see Equation (17)) establishes the thermal comfort zone, that is the minimum and maximum allowed levels for the predicted output, the PMV index. This constraint is used to guarantee a comfortable situation for the users of the building, since a PMV index value out of this range will affect users' productivity. The second constraint (see Equation (18)) fixes the physical hard constraints of the fan coil unit installed at the characteristic room of the CIESOL building, that is it takes into account the minimum and maximum fan coil speed that can be reached with the actuator. This kind of problem is solved through a quadratic programming (QP) solver.

$$
\begin{gathered}
Y_{\text {min }} \leq \widehat{Y}_{P M V}(k+j \mid k) \leq Y_{\text {max }} \quad \forall j=0, \cdots, N_{u}-1 \\
u_{\text {min }} \leq u(k+j \mid k) \leq u_{\max } \quad \forall j=0, \cdots, N_{u}-1
\end{gathered}
$$

Thence, the economic MPC controller calculates a fan coil speed $\left(V_{F a n}\right)$ comprised within the range $[0 \%, 100 \%]$. Nonetheless, the fan coil available at the characteristic room of the CIESOL building is implemented by means of discrete on/off actions being necessary to convert the continuous estimated fan position to a control action, which can be supplied to a discrete actuator. To do that, a pulse width modulation (PWM) signal has been used [31]. It has a cycle period (C) of $120 \mathrm{~s}$, an internal sample time of a second, a maximum time for which the control signal is fixed to $100 \%\left(T_{o n}\right)$ of $120 \mathrm{~s}$ and a minimum time for which the control signal is fixed to $0 \%\left(T_{o f f}\right)$ of $0 \mathrm{~s}$. Additionally, to avoid stress in the fan coil unit, its fan is not connected unless the fan position control signal is greater than $33 \%$.

\section{Results and Discussion}

In this section, several simulation scenarios are considered in order to prove the performance of the proposed control strategy presented in Section 2.4. The controller is tested through the room simulator, that is the non-linear model based on first principles, which has been described in Section 2.3. The simulation tools for this purpose were MATLAB and Simulink from the MathWorks company.

\subsection{Preliminary Considerations}

In this paper, the energy price is used to weight the control action calculated by the MPC. This energy price is predicted through the DAP, which is supplied by OMIE. OMIE is a company that manages the entirety of the markets (daily and intraday) for the Iberian Peninsula [32], and its operating model is the same as the one applied by many other European markets. From its website, an hourly-based mean energy price for Spain during July of 2016 has been calculated and used in the controller; see Figure 5.

It is important to highlight that the energy price is given by OMIE in $(€ / M W)$, for this reason, the price per Watt is so inexpensive. As is possible to see in Figure 5, the energy price is not constant along the day, since during dawn, it has its lease expensive values, whereas in the afternoon, it reaches the most expensive prices. On the other hand, the energy consumption of the HVAC follows four operation modes, which are summarized in Table 4, where each operation mode is related to its energy consumption. This energy consumption has been measured through several tests in which the fan coil 
has been set at constant speed and its energy consumption has been measured with a power meter. As the reader can see, the HVAC system spends more energy to turn on than to increase its speed. This fact is due to part of the energy being used to exceed the thermal inertia of the air zone of the HVAC. Therefore, in the second operation mode, about $50 \mathrm{Wh}$ are used to exceed the thermal inertia of the air zone, and $17.95 \mathrm{Wh}$ are used to increase the HVAC motor speed until $33 \%$. We can conclude that at the time to turn on the HVAC, $50 \mathrm{Wh}$ are spent to exceed the thermal inertia of the air zone and $0.5 \mathrm{Wh}$ to increase its speed one percent.

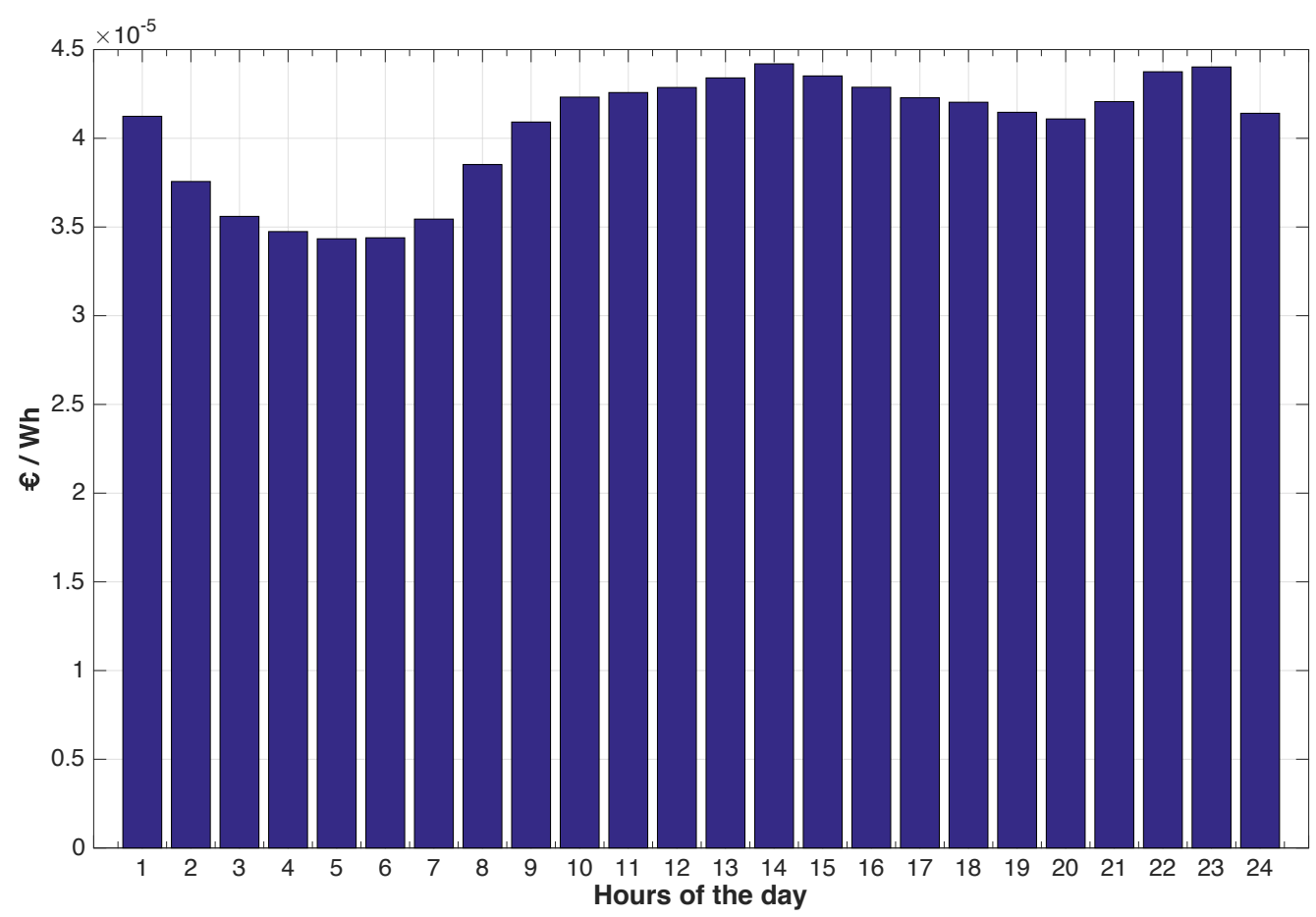

Figure 5. Mean energy price $(€ / W)$ for Spain during July 2016.

Table 4. HVAC operation modes and the associated energy consumption.

\begin{tabular}{cc}
\hline HVAC Mode & Energy Consumption (Wh) \\
\hline $0 \%$ & 0 \\
$33 \%$ & 67.95 \\
$66 \%$ & 79.80 \\
$100 \%$ & 95.05 \\
\hline
\end{tabular}

As has been pointed out in Section 2.1.1, optimal thermal comfort is obtained when PMV $=0$, but it makes no sense to reach this optimal thermal comfort and, therefore, to spend energy, if nobody is inside the laboratory. Thus, for the simulation tests, the typical occupancy of the laboratory is used. It is assumed that the laboratory is fully occupied during working time, which is from 8 a.m. -5 p.m. with a break of one hour for lunch from 2 p.m.-3 p.m. In these hours, the controller will try to get an optimal thermal comfort, $\mathrm{PMV}=0$, since people are inside the laboratory, but during the non-working hours, the PMV set-point will be switched to 0.3 , which will be considered as a "ready" state, in order to save energy when the laboratory is empty; and at the same time, the PMV is keeping close to zero; thus, it can be easily driven to the optimal on working hours.

Finally, three simulation scenarios are considered: (i) in the first one, the response of the system controlled by the economic MPC is compared with the free response of the system when any controller is in charge to maintain the thermal comfort; (ii) in this scenario, the response of the MPC is analyzed through different energy prices; and (iii) in the third scenario, a discrete actuator is considered. All of 
the scenarios have been simulated through Simulink in a MacBook Pro with an Intel Core i5 processor at $2.9 \mathrm{GHz}$ and with a RAM memory of $8 \mathrm{~GB}$. To perform the simulation tests, data saved during one July working day in CIESOL building have been used. In Figure 6, it is possible to see some of these data, specifically: (i) solar radiation, the orange solid line in the top graph; (ii) outdoor temperature, the blue line in the second graph; (iii) outdoor relative humidity, the green solid line in the third graph; and (iv) outdoor wind speed, the red solid line in the bottom graph. At first sight, it is possible to highlight that the behavior of the solar radiation and the outdoor temperature is similar since both signals have their maximum values at solar midday and the minimum ones during the night. On the other hand, the relative humidity has the opposite behavior, with the maximum values at dawn and the minimum ones during midday. Finally, the wind speed has a random behavior between 2 and $4 \mathrm{~m} / \mathrm{s}$, since it does not follow any pattern.
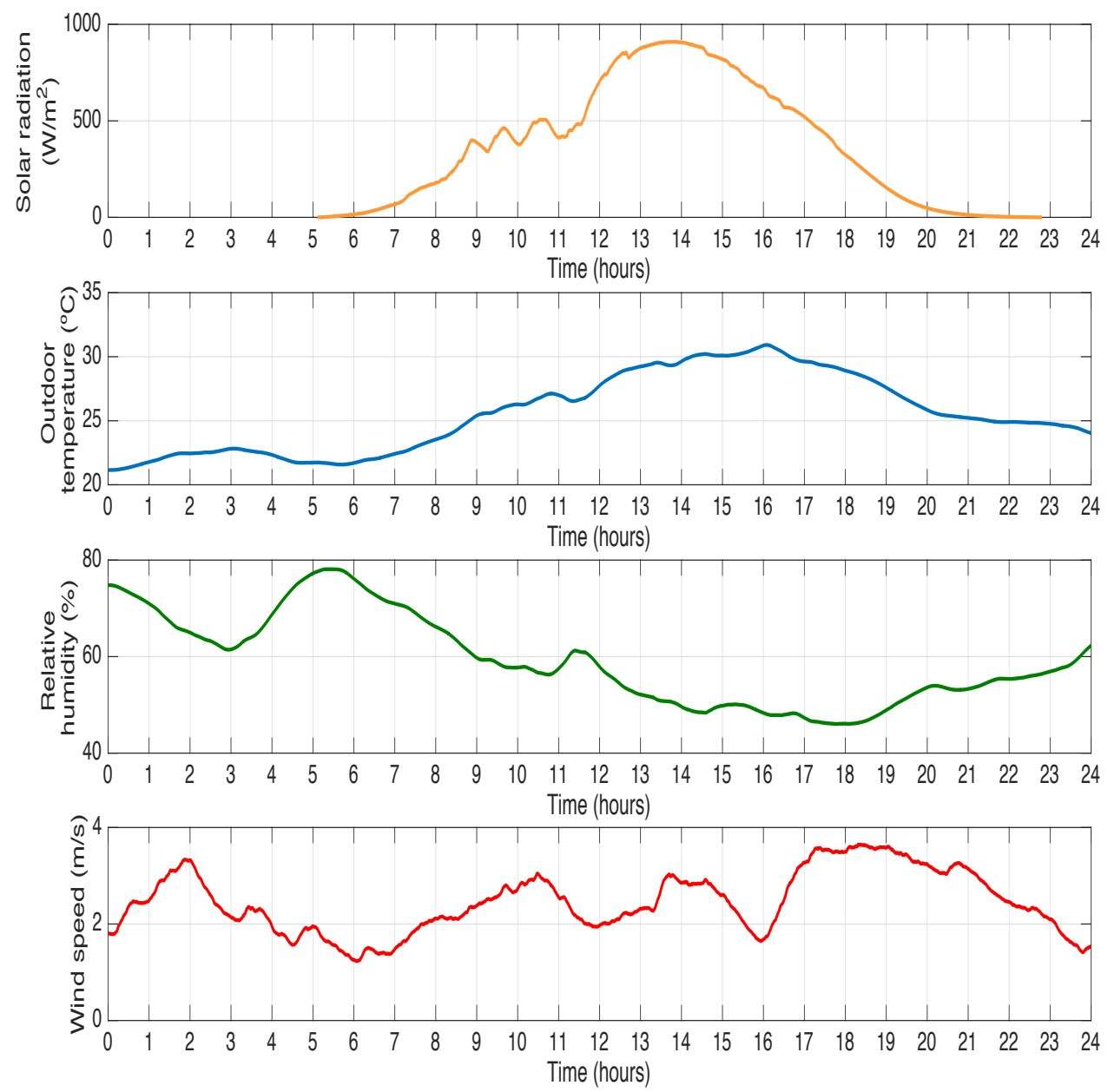

Figure 6. Weather signals during the working day used for simulation tests.

\subsection{Simulation Scenario: Typical Case}

In this first scenario, the considerations pointed out in the previous subsection are taken into account. The economic MPC tries to reach an optimal comfort, i.e., PMV =0, when the laboratory is occupied, and the HVAC is considered as a continuous actuator, that is its speed can get any value between $0 \%$ and $100 \%$. Moreover, the control results will be compared with the free response of the system, that is the natural dynamic of the laboratory when the HVAC is turned off. The results are shown in Figure 7. 

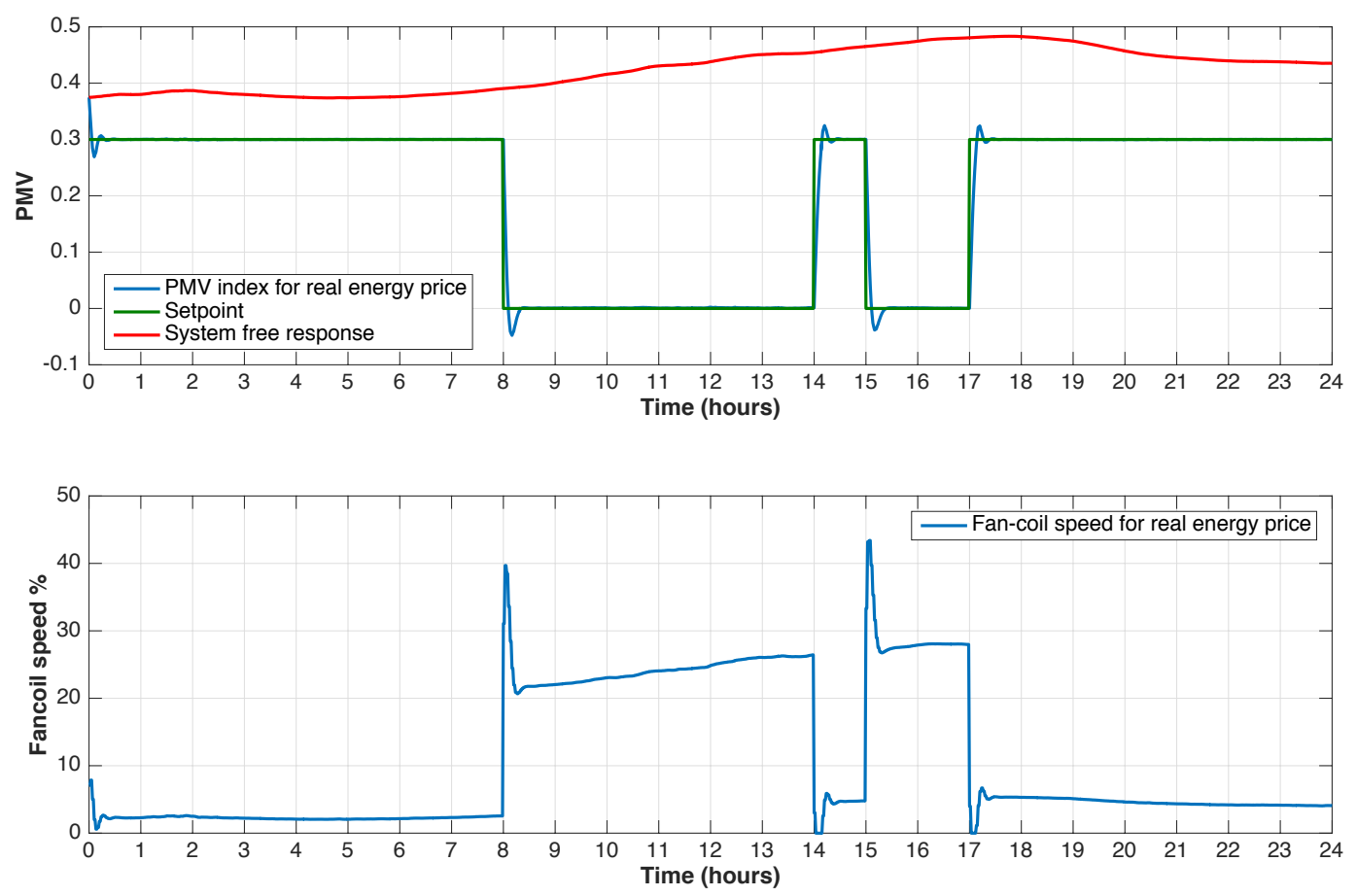

Figure 7. Results for the typical case versus the free response of the system.

In the top graph of Figure 7, the results of the proposed controller, blue solid line, together with the free response of the system, red solid line, and the PMV reference, green solid line, are plotted, whereas in the bottom graph, the HVAC speed in \%, which is calculated by the economic MPC each sample time, is shown. It is possible to see how the economic MPC is able to reach the desired PMV reference along the day, as an optimal thermal comfort, PMV $=0$, during working hours as the 'ready' state, PMV $=0.3$, when anybody is in the laboratory. The PMV reference is reached with a slight overshoot in its dynamics due to the fact that the MPC has been calculated through a linear model and is tested with the room simulator presented in Section 3, that is a non-linear model based on first principles [26]. Thus, there are some system dynamics that the MPC has not taken into account, but is able to correct them at the time to maintain each time the PMV at the desired value. It is important to highlight that the free system response shows that if no controller is in charge to maintain thermal comfort, although a bioclimatic building is considered, a warm thermal sensation is obtained along the day. This thermal sensation is warmer in the afternoon due to outdoor weather conditions, mainly due to outdoor temperature and solar radiation, as can see in Figure 6. For the same reason, the economic MPC must increase the control action during these hours, from 12 a.m.-6 p.m.

The total power spent by the economic MPC can be calculated by integrating the control signal, which appears in the bottom graph of Figure 7 . The result is $758 \mathrm{~W}$, where $200 \mathrm{~W}$ are dedicated to turn on the HVAC system four times, as the reader can see in the bottom graph of Figure 7, and $558 \mathrm{~W}$ to increase the fan coil speed. On the other hand, the simulation time was only $256 \mathrm{~s}$.

\subsection{Simulation Scenario: Energy Cost Increased}

In this scenario, the energy cost along the day (see Figure 5) is increased by a factor of five in order to see how the economic MPC looks for a tradeoff between the users' thermal comfort and the energy used to get this thermal comfort. The results are presented in Figure 8. In the top graph is shown the PMV reference, green solid line, and the responses of the economic MPC with real energy price and with augmented energy price, blue and red solid lines, respectively. On the other hand, in the bottom graph, the control actions of the economic MPC with real and augmented energy prices are plotted, blue and red solid lines, respectively. It is possible to note that the thermal comfort driven by 
the economic MPC with an augmented energy price does not reach an optimal value, i.e., PMV $=0$, in the midday, since the controller decides to maintain the PMV close, but not equal to zero. This fact is due to the fact that, during the midday, the control action must be high in order to counteract the thermal effects of outdoor temperature and solar radiation, and since in this case, the energy price compared to the typical case is higher, the MPC decides to slightly decrease the control action. Even so, the PMV value during the midday is close to zero, and it is possible to consider that a good users' thermal comfort is obtained.
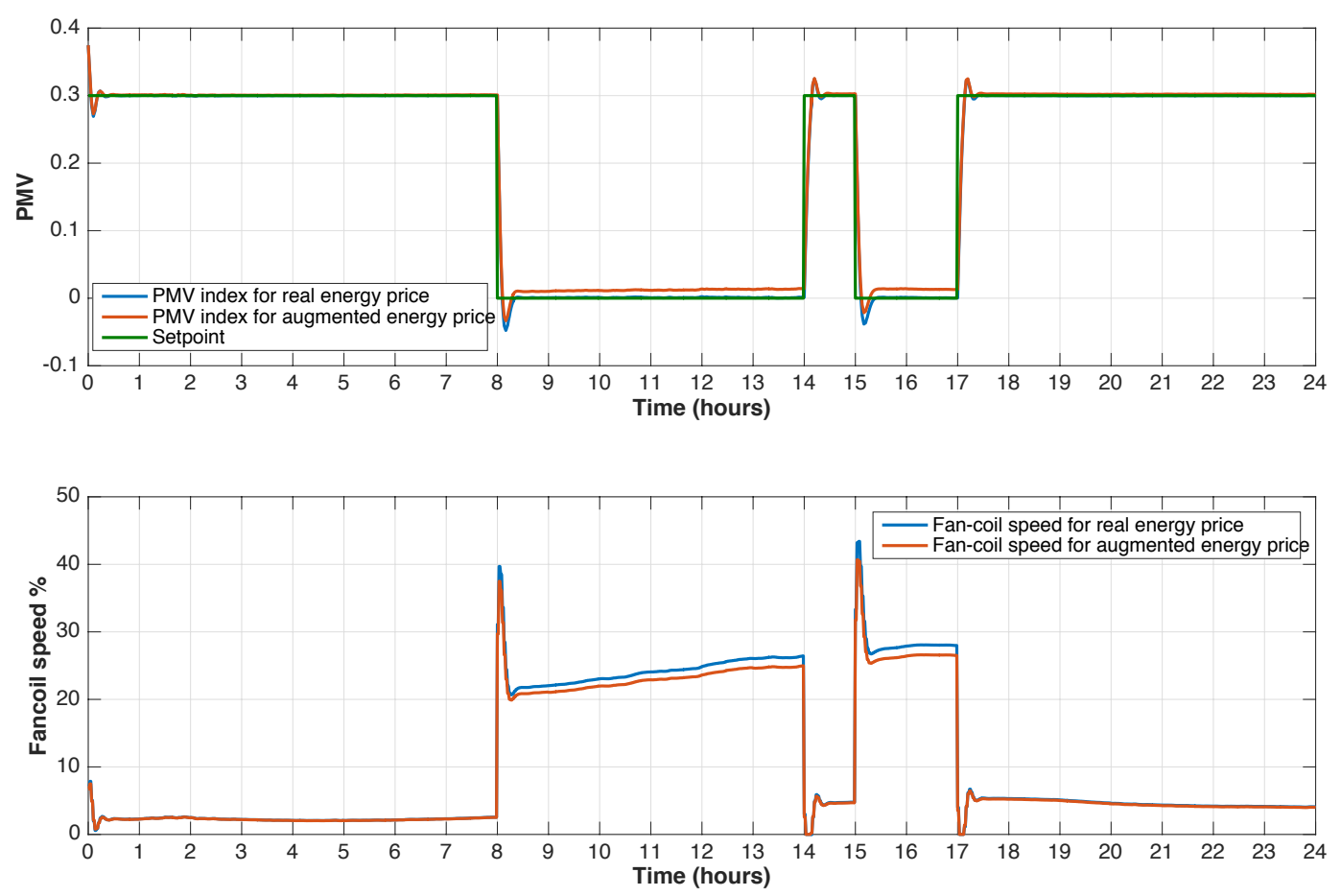

Figure 8. Results for the typical case versus augmented energy price.

In this case, the total power spent by the economic MPC with the energy price augmented is $733 \mathrm{~W}$, a saving of $25 \mathrm{~W}$; whereas, in the typical case, $200 \mathrm{~W}$ are dedicated to turn on the HVAC system four times and $533 \mathrm{~W}$ to increase the fan coil speed. The time spent to simulate the model, $259 \mathrm{~s}$, was similar to the previous scenario.

\subsection{Simulation Scenario: Discrete Actuator}

Since the the usual industrial fan coils are implemented through discrete on/off actions in this simulation scenario, a discrete actuator has been considered, that is the only control actions can be turning off the fan coil, $0 \%$, or turning it on, $100 \%$, but not any intermediate value. Thus, it is necessary to transform the computed fan coil power percentage in such a way that the control action can be provided through a discrete actuator. The usual way of doing this is through a PWM signal [31]. The results can be seen in Figure 9, where the graphs placed on the left side are the PMV and the control action (top and bottom graph, respectively), whereas the graphs placed on the right side are a zoom over one hour, from 8 a.m. -9 a.m., in order to enable a closer inspection of the system dynamics. Moreover, in the bottom graphs, the solid blue line is the continuous signal calculated by the economic MPC, and the red solid line is its equivalent discrete version calculated through the PWM. As the reader can notice, in this scenario, the settling time of the system is the same as in the case of using the continuous actuator over $20 \mathrm{~min}$ (see Figure $9 \mathrm{~b}$ ) but in this case, the system dynamics has an oscillatory behavior due to the on/off nature of the actuator. During the day, the optimal PMV state, PMV =0, and the "ready" PMV state, PMV = 0.3, are reached, but the system fluctuates over these values. 

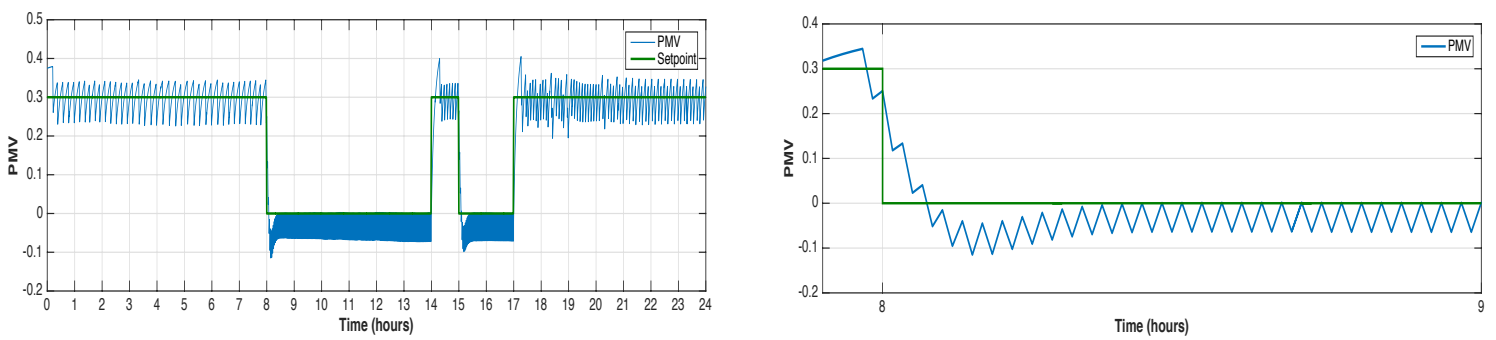

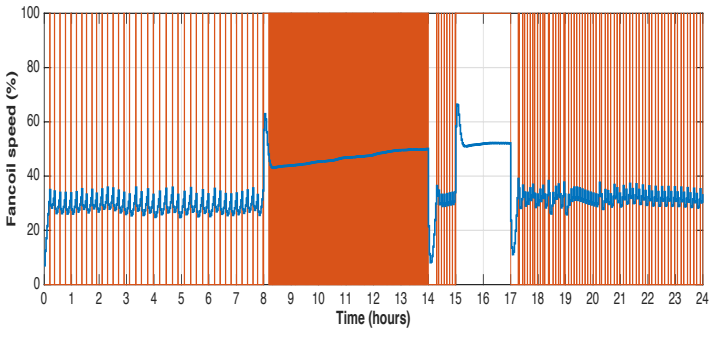

(a)

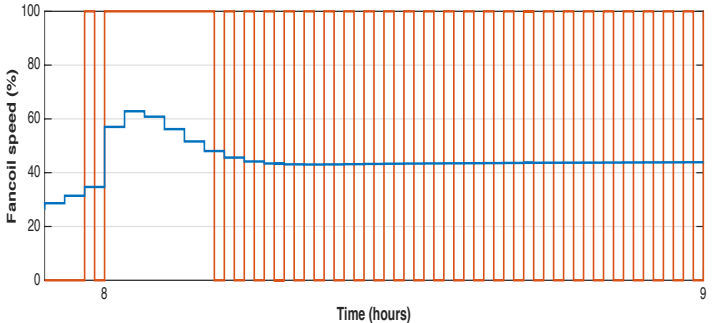

(b)

Figure 9. Results for the typical case with on/off actuator (a) and zoom over one hour (b).

From a power consumption point of view, the total power spent by the economic MPC is increased due to the discrete nature of the actuator. The power spent is $22,408 \mathrm{~W}$, where most part of this power, $20,900 \mathrm{~W}$, is used to turn on he HVAC system 418 times during the day and only $1508 \mathrm{~W}$ to increase the fan coil speed. In this scenario, the time spent to simulate it was longer due to the multiple changes in the control action; thus, it was $612 \mathrm{~s}$. As the reader can seen, in the case of having a discrete actuator available instead of a continuous one, the PMV index is reached with fluctuations, and a higher energy consumption is obtained, without taking into account that in this case, the actuator stress is huge. Therefore, as the discrete operator implies a higher money cost, the reader can consider the money spent in buying a continuous actuator instead of using the discrete one.

\section{Conclusions and Future Works}

In this paper, an economic MPC controller has been developed based on a linear model derived from a non-linear one based on first principles. This model captures the dynamics of a laboratory, which is part of the research center CIESOL. In order to obtain an optimal thermal comfort for the laboratory users, whereas saving energy is done, a control strategy, which takes into account the hourly energy price variation in Spain through the DAP, is developed. Therefore, three simulation scenarios are shown to test the proposed control system, in the first one, the control system is compared with the free response of the system; in the second one, the control system is tested with different DAPs; and finally, in the third one, a discrete actuator is considered. In all of the simulation scenarios, the proposed control system has demonstrated that it is able to achieve a tradeoff between users' thermal comfort and the amount of energy spent to reach this thermal comfort. This is the main conclusion of this work: the proposed control strategy is able to manage the energy spent through the use of the DAP, whereas the users' thermal comfort is maximized. Specifically, when the energy price is expensive, the controller decides not to reach an optimal thermal comfort, PMV $=0$, but rather very close to it. The saved energy could seem small, since the controller is tested in only one room, but it will increase if the proposed control system is applied to all of the rooms that form a building.

As a future research work, the proposed control strategy will be tested with other non-linear models developed in Dymola or TRNSYS. In this way, the theoretical performance of the MPC could be compared with the performance obtained with this highly detailed model. Furthermore, in order to obtain real results, the proposed control strategy will be integrated into the SCADA system of the 
CIESOL building to apply it in a laboratory. Such measurements will provide significant data and results for further studies.

Acknowledgments: This work has been partially funded by the following project: DPI2014-56364-C2-1-R (financed by the Spanish Ministry of Science and Innovation and EU-ERDF funds) and Competitiveness and ERDF funds, and by the Fundación Iberdrola España, through its Call for Research on Energy and Environment Grants "ENERGY FOR RESEARCH". Yaser Alamin is a fellow of the MARHABA, an Erasmus Mundus Lot 3 project. María del Castilla is a fellow of the Spanish Juan de la Cierva-Formación contract program. José Domingo Álvarez is a fellow of the Spanish Ramón y Cajal contract program. Antonio Ruano would like to acknowledge the support of the Portuguese Foundation for Science \& Technology, through IDMEC, under LAETA, Project ID/EMS/50022/2013.

Author Contributions: All authors have participated in preparing the research from the beginning to the end, such as establishing research design, method and analysis. All authors discussed and finalized the analysis results to prepare manuscript according to the progress of research.

Conflicts of Interest: The authors declare no conflict of interest.

\section{References}

1. 2010/31/UE. Directive 2010/31/UE of the European Parliament and of the Council of 19 May 2010 on the Energy Performance of Buildings. 2010. Available online: http:/ / eur-lex.europa.eu/LexUriServ/LexUriServ. do?uri=OJ:L:2010:153:0013:0035:EN:PDF (accessed on 17 November 2016).

2. EPBD. 2016. Available online: http://www.epbd-ca.eu/ (accessed on 17 November 2016).

3. Yang, I.H.; Yeo, M.S.; Kim, K.W. Application of artificial neural network to predict the optimal start time for heating system in building. Energy Convers. Manag. 2003, 44, 2791-2809.

4. Pérez-Lombard, L.; Ortiz, J.; Pout, C. A review on buildings energy consumption information. Energy Build. 2008, 40, 394-398.

5. Moroşan, P.D.; Bourdais, R.; Dumur, D.; Buisson, J. Building temperature regulation using a distributed model predictive control. Energy Build. 2010, 42, 1445-1452.

6. Diakaki, C.; Grigoroudis, E.; Kolokotsa, D. Towards a multi-objective optimization approach for improving energy efficiency in buildings. Energy Build. 2008, 40, 1747-1754.

7. Diakaki, C.; Grigoroudis, E.; Kabelis, N.; Kolokotsa, D.; Kalaitzakis, K.; Stavrakakis, G. A multi-objective decision model for the improvement of energy efficiency in buildings. Energy 2010, 35, 5483-5496.

8. Carli, R.; Dotoli, M.; Pellegrino, R.; Ranieri, L. A Decision Making Technique to Optimize a Buildings' Stock Energy Efficiency. IEEE Trans. Syst. Man Cybern. Syst. 2016, PP, 1-14.

9. Camacho, E.F.; Bordons, C. Model Predictive Control; Springer: London, UK, 2004.

10. Pčolka, M.; Žáčeková, E.; Robinett, R.; Čelikovskỳ, S.; Šebek, M. Bridging the gap between the linear and nonlinear predictive control: Adaptations for efficient building climate control. Control Eng. Pract. 2016, 53, 124-138.

11. Carrascal, E.; Garrido, I.; Garrido, A.J.; Sala, J.M. Optimization of the Heating System Use in Aged Public Buildings via Model Predictive Control. Energies 2016, 9, 251.

12. Ascione, F.; Bianco, N.; De Stasio, C.; Mauro, G.M.; Vanoli, G.P. Simulation-based model predictive control by the multi-objective optimization of building energy performance and thermal comfort. Energy Build. 2016, 111, 131-144.

13. Afram, A.; Janabi-Sharifi, F. Effects of dead-band and set-point settings of on/off controllers on the energy consumption and equipment switching frequency of a residential HVAC system. J. Process Control 2016, 47, 161-174.

14. Michailidis, I.T.; Korkas, C.; Kosmatopoulos, E.B.; Nassie, E. Automated control calibration exploiting exogenous environment energy: An Israeli commercial building case study. Energy Build. 2016, 128, 473-483.

15. Marvuglia, A.; Messineo, A.; Nicolosi, G. Coupling a neural network temperature predictor and a fuzzy logic controller to perform thermal comfort regulation in an office building. Build. Environ. 2014, 72, 287-299.

16. Jazizadeh, F.; Ghahramani, A.; Becerik-Gerber, B.; Kichkaylo, T.; Orosz, M. User-led decentralized thermal comfort driven HVAC operations for improved efficiency in office buildings. Energy Build. 2014, 70, 398-410.

17. American Society of Heating and Air-Conditioning Engineers (ASHRAE). ASHRAE Handbook-Fundamentals; Refrigerating American Society of Heating and Air-Conditioning Engineers: Atlanta, GA, USA, 2009. 
18. ANSI/ASHRAE 55. Thermal Environmental Conditions for Human Occupancy; American Society of Heating Ventilating and Air-Conditioning Engineers: Atlanta, GA, USA, 2004.

19. Moderate Thermal Environments. Determination of the PMV and PPD Indices and Specification of the Conditions for Thermal Comfort; ISO7730; International Organisation for Standardisation: Geneva, Switzerland, 1994.

20. Fanger, P.O. Assessment of man's thermal comfort in practice. Br. J. Ind. Med. 1973, 30, 313-324.

21. Fanger, P.O. Thermal Comfort Analysis and Applications in Environment Engineering; McGraw Hill: New York, NY, USA, 1972.

22. Orosa, J.A. Research on General Thermal Comfort Models. Eur. J. Sci. Res. 2009, 27, 217-227.

23. Liang, J.; Ruxu, D. Thermal comfort control based on neural network for HVAC application. In Proceedings of the 2005 IEEE Conference on Control Applications, Toronto, ON, Canada, 28-31 August 2005; pp. 819-824.

24. Tse, W.L.; Chan, W.L. Real-time measurement of thermal comfort by using an open networking technology. Measurement 2007, 40, 654-664.

25. Institute for Energy Diversification and Saving (IDAE). Reglamento de Instalaciones Térmicas en los Edificios; Technical Report; Ministerio de Industria, Turismo y Comercio: Madrid, Spain, 2007.

26. Castilla, M.; Álvarez, J.; Rodríguez, F.; Berenguel, M. Advances series in Industrial Control. In Comfort Control in Buildings; Springer: London, UK, 2014; p. 237.

27. CIESOL. Available online: http:/ / www.ciesol.es (accessed on 17 November 2016).

28. Castilla, M.; Álvarez, J.; Normey-Rico, J.; Rodríguez, F. Thermal comfort control using a non-linear MPC strategy: A real case of study in a bioclimatic building. J. Process Control 2014, 24, 703-713.

29. Castilla, M.; Álvarez, J.D.; Berenguel, M.; Rodríguez, F.; Guzmán, J.L.; Pérez, M. A comparison of thermal comfort predictive control strategies. Energy Build. 2011, 43, 2737-2746.

30. Rivera, D.; Jun, K. An integrated identification and control design methodology for multivariable process systems applications. IEEE Control Syst. Mag. 2000, 20, 25-37.

31. Salsbury, T.I. A new pulse modulation adaptive controller (PCMA) applied to HVAC systems. Control Eng. Pract. 2002, 10, 1357-1370.

32. Omie. 2016. Available online: http://www.omie.es/en/inicio (accessed on 17 November 2016).

(C) 2017 by the authors. Licensee MDPI, Basel, Switzerland. This article is an open access article distributed under the terms and conditions of the Creative Commons Attribution (CC BY) license (http:/ / creativecommons.org/licenses/by/4.0/). 